\title{
Putative Male - Male Agonistic Behaviour in Free-Living Zebra Sharks, Stegostoma fasciatum
}

\author{
Juerg M. Brunnschweiler ${ }^{1, *}$ and Harold L. Pratt, Jr. ${ }^{2}$ \\ ${ }^{I}$ Swiss Federal Institute of Technology; ${ }^{2}$ Center for Shark Research, Mote Marine Laboratory
}

\begin{abstract}
We analysed digital still photographs of two interacting free-living male zebra sharks. The recorded behaviours are similar in appearance to some male - female courtship and mating patterns in elasmobranchs and several of the positions are similar to or resemble reproductive behaviours known from other species. We discuss two possible hypotheses that may explain the interaction, sexual behaviour and an agonistic behaviour. We reject the same-sex hypothesis and propose that the event was of agonistic nature.
\end{abstract}

Key Words: Agonistic behaviour, Elasmobranch, Homosexual, Male-male mating, Mating behaviour, Pectoral bite, Shark, Sexual behaviour, Stegostoma fasciatum, Zebra shark.

\section{INTRODUCTION}

Human observation and inferences made from still images provide invaluable information about animal behaviour. However, these techniques have generated relatively little data on elusive species, such as many marine animals. For example, many facets of the behaviour of free-living cartilaginous fishes are still poorly known largely because of the lack of direct observations and due to the difficulty and relative rarity of in situ field studies. This is particularly true for social and sexual behaviour. For example, agonism is a class of behaviour that is important to the social dynamics in animals of many taxa but there are few records of the social organisation and interaction in elasmobranchs from the wild. Observations of brief novel behaviours in free-living sharks are usually very difficult to document but many have proven to be valuable to quantitatively describe such behaviours [14]. The analyses of video footage and still photographs have, for example, furthered our understanding of elasmobranch agonistic and sexual behaviour [5-10]. Descriptive observations by researchers under natural conditions can generate hypotheses which eventually lead to experimental research [11].

Agonistic behaviours are widespread among animals. Shark agonistic displays are best known in the grey reef shark (Carcharhinus amblyrhynchos) [12], but are known from a variety of shark species [10]. However, such displays are mostly observed and described in a shark - human context and less frequently as an important part of intraspecific behaviour such as establishing, for example, dominance hierarchies or territorial display. Elasmobranchs do exhibit dominance hierarchies within both wild and captive reproductively active groups [7, 13-14], but direct observations of agonistic interactions and evidence of how they maintain dominance hierarchies are still very limited.

*Address correspondence to this author at the Swiss Federal Institute of Technology, Euresearch Zurich, Careum, Moussonstrasse 2, CH-8044 Zurich, Switzerland; Tel: +41-44-6345355; Fax: +41-44-6345351; E-mail: juerg@gluecklich.net
Action patterns performed in agonistic contexts are typically also used in other contexts, such as predatory behaviour, anti-predatory behaviour, and mating $[10,15]$. For example, elasmobranch fishes exhibit a series of complex courtship and mating behaviours in which males inflict bite wounds to the body of female mates [7, 16-17]. While bite wounds occur primarily on females, males are also the target of intrasexual biting [18] and such bite marks are usually attributed to aggressive interactions between consexuals for access to females. In both male and female elasmobranchs, not all bite marks result from reproductive activities, but possibly result from agonistic interactions [19].

Here, we present digital still photographs of two male zebra sharks (Stegostoma fasciatum) that engage in what looks similar to mating. Mating events in elasmobranchs begin with 'precopulatory' encounters usually starting with a pectoral 'grasp', which may or may not lead to and include copulation $[8,20]$. Pair contact is usually maintained by the male's tight oral grasp of one of the female's pectoral fins. Our brief photo record suggests two possible hypotheses for the nature of the observed behaviour, namely sexual behaviour and agonistic behaviour.

\section{MATERIALS AND METHODOLOGY}

The zebra shark is an inshore tropical shark of the IndoWest Pacific that is very common on coral reefs [21], but the behaviour and social organisation of this oviparous species is little known, and it is usually referred to as solitary. Digital still photographs of two sexually mature male zebra sharks were taken by a SCUBA diver at a small reef patch east of Phuket Island, Thailand. The location is well known for zebra sharks, and this species can be encountered year round. Local dive guides report to regularly seeing, usually solitary, male and female zebra sharks. Two male zebra sharks were detected on 13 April 2007 at 1135 hours at a depth of $25 \mathrm{~m}$. Sea water temperature was $28{ }^{\circ} \mathrm{C}$ and there was no noticeable water current. Visibility was estimated to be $10 \mathrm{~m}$. The interaction was documented with 15 still photographs for a total duration of 245 seconds from a distance of $2.5 \mathrm{~m}$. The 
Table 1. Static Description of the Behaviours Performed by the Two Male Zebra Sharks. Grasping the Right Pectoral Fin of Male B by Male A, Male B being on its Back and Male B Bending its Tail Towards Male A is only Described the First Time it is Visible in Fig. (1 a, b, d), but Continues throughout the Sequence from there on

\begin{tabular}{|c|c|}
\hline & Description \\
\hline Fig. (1a) & Male A grasping the right pectoral fin of male B from a perpendicular position \\
\hline Fig. (1c) & Male A on the other side of male B in a perpendicular head-down position \\
\hline Fig. (1d) & $\begin{array}{c}\text { Male A perpendicular to male B. Male B arches its body away and bends its tail towards male A. The claspers of both sharks are } \\
\text { visible }\end{array}$ \\
\hline Fig. (1e) & Both sharks in the same position as in Fig. (1d) with male B turned $90^{\circ}$ in an anticlockwise direction \\
\hline Fig. (1f) & $\mathrm{B}$ turned around $90^{\circ}$ in an anticlockwise direction. Male $\mathrm{A}$ is in a head-on position to male $\mathrm{B}$ \\
\hline Fig. (1g) & $\begin{array}{c}\text { Male B slightly more to the right with regard to structure II and male A turned } 90^{\circ} \text { in an anticlockwise direction. Male A in } \\
\text { perpendicular position }\end{array}$ \\
\hline Fig. (1n-o) & $\begin{array}{l}\text { Both sharks slightly further up with regard to structure I and male B turned } 90^{\circ} \text { in an anticlockwise direction resulting in a } \\
\text { perpendicular position of male A in relation to male B }\end{array}$ \\
\hline
\end{tabular}

two animals were not noticeably disturbed by the presence of the diver, and no other shark species and/or conspecifics were seen or recorded during the interaction.

\section{RESULTS}

Table 1 presents a static description of the behaviours documented in Fig. (1). The spatial area on which the two sharks were observed for the total duration of 245 seconds is relatively small and estimated to be $5 \mathrm{~m}^{2}$. At least one of the rocky structures (I, II, III) on the seafloor can be seen very close to the sharks on every picture (Fig. 1a-o). A dynamic description of the event begins with the photo record of male A already grasping the right pectoral fin of a similarly sized male B from a perpendicular position (Fig. 1a). A continuous biting of the right pectoral fin of male B by male A can be seen throughout the sequence (Fig. 1a-o). Fig. (1b) shows male B turned $90^{\circ}$ around its body axis on its back. This turnaround is caused by male B swimming slightly upwards to the right. Male A moves its body to the left and turns $180^{\circ}$ in an anticlockwise direction around its body axis hovering over male B in a head-down position. This results in male A twisting male B's right pectoral fin (Fig. 1c). While male A is pushing male B to the left, both individuals can be clearly identified as adult males (Fig. 1d). As a possible result of male A pushing male B to the left in a anticlockwise direction (Fig. 1d-e), the tail of male B bends towards male A. Male B's tail remains bended towards the body of male A for the rest of the sequence (Fig. 1f-o). Male A continues to move male $\mathrm{B}$ in an anticlockwise direction (Fig. 1f-g) until both sharks are turned $180^{\circ}$ compared to Fig. (1d). The time it takes male A to move itself and male B $180^{\circ}$ is 25 seconds (Fig. 1d-g). Male A then aligns its body with male B (Fig. 1h), and both zebra sharks remain in that position for $95 \mathrm{sec}-$ onds (Fig. 1h-k). During this sequence, male B is motionless and rigid with its back on the substrate, its tail underneath male A, and its right pectoral fin mouthed by shark A and twisted more than $90^{\circ}$ forward around the fins' longitudinal axis. Because of the time gap of more than a minute between Fig. (1k) and (11), an accurate dynamic description of the behaviour of the two male zebra sharks is not possible. Compared with Fig. (1k), the next photograph (Fig. 11) shows male $\mathrm{B}$ more to the right and male A turned $90^{\circ}$ in a clockwise direction to the right resulting in a head-on position. Male A then moves its body $270^{\circ}$ in an anticlockwise direction turning around male $\mathrm{B} 90^{\circ}$ (Fig. 1m). This is followed by male A pushing male B upwards and turning it $90^{\circ}$ in an anticlockwise direction (Fig. 1n-o).

To summarise our observation of interactive factors in the image set: From the appearance and condition of the fully developed claspers (Fig. 1d), both sharks are of adult size. Claspers in all images were noted to be quiescent and never in an erectile state. The claspers are not hematose or swollen or noticeably abraded. Dermal tooth cuts, healed or fresh, do not occur on either shark's fins or bodies.

\section{DISCUSSION}

Assigning a sexual nature to the recorded behaviour necessarily implies that the two adult male zebra sharks are engaging in homosexual behaviour. The recorded behaviours are similar in appearance to some male - female courtship and mating patterns in elasmobranchs and several of the positions are similar to or resemble reproductive behaviours known from other species [7]. These are: 'pectoral bite' (in our case, the male bites and holds the other male's pectoral fin) of the right pectoral fin of male B by male A (Fig. 1a-o) and 'lay on back' [male $\mathrm{B}$ is motionless and rigid with back on the substrate and pectoral fins outstretched, Fig. (1h-k)]. While 'positioning and alignment' [male A moves male B 

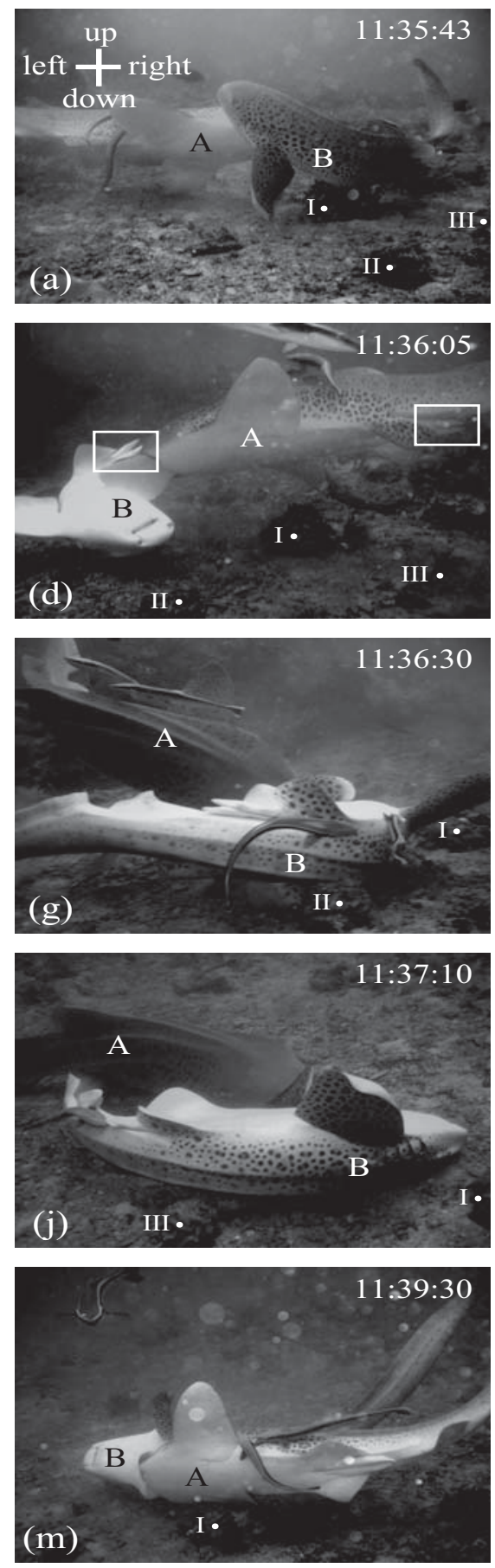
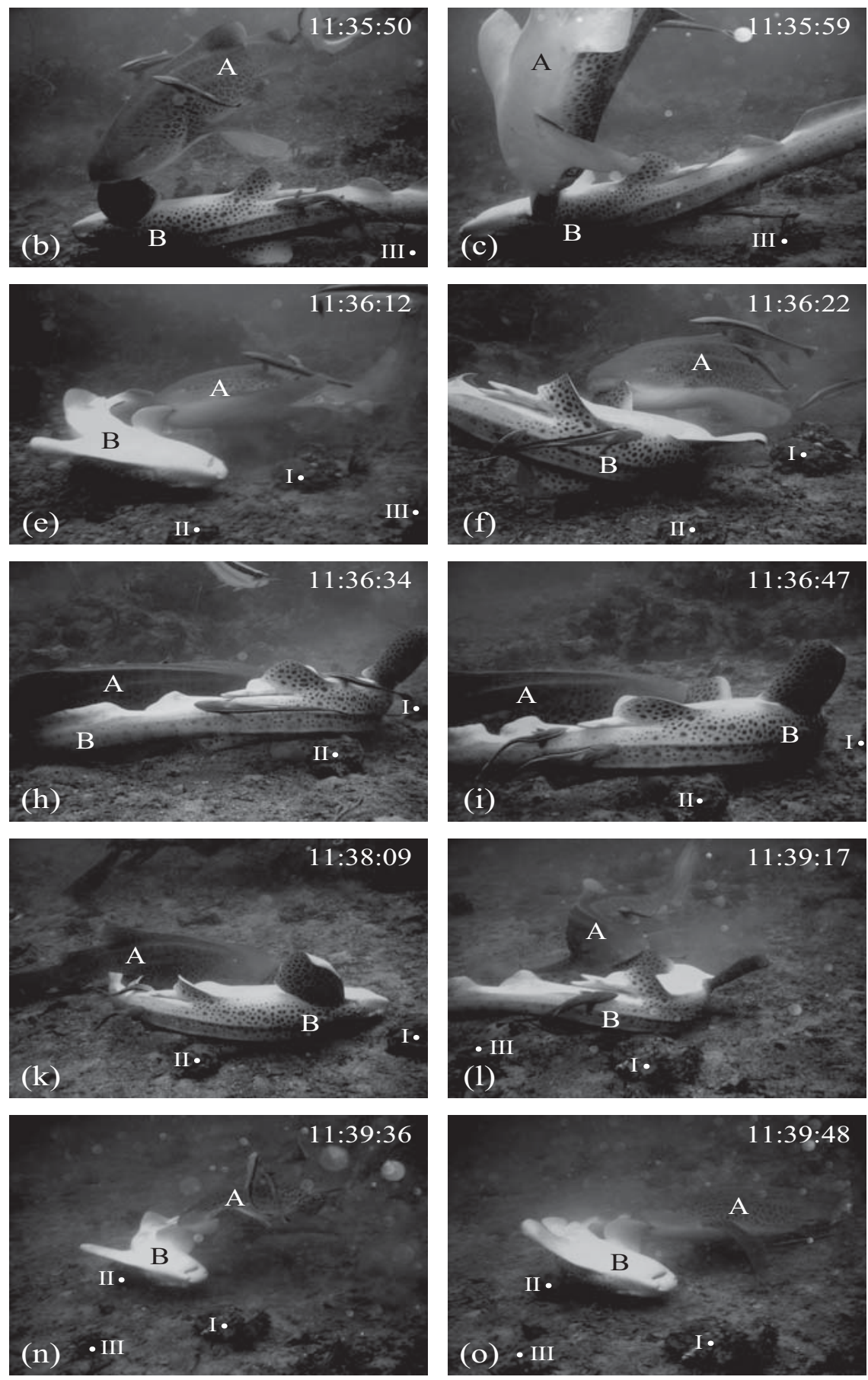

Fig. (1). Digital still photographs of the two male zebra sharks (A and B). Number in the upper right corner is time (hour:minute:second); I, II and III are structures on the seafloor that are used for spatial orientation; up, down, left and right are pictured only on (a). ${ }^{\circ}$ values in the text (if no turning around a body axis is described) are relative to structures I, II and III. Note that claspers in all images are quiescent and never in an erectile state. The echeneids that can be seen on each photograph are Echeneis naucrates.

from the perpendicular to the parallel position, Fig. (1d-h)] is a reproductive behaviour known from other shark species [7], in our case, the positioning is likely coincidental to male B getting grabbed and pushed around by male A. The dynamic description of the interaction between the two adult male zebra sharks assumed that male $\mathrm{A}$ is the active shark moving around shark B. However, shark A is not necessarily initiating all the movements. While it is safe to assume that male A turns male B on its back (Fig. 1a-c), it could well be that the body movements of male B lying on its back on the substrate move around male $\mathrm{A}$ as a consequence of an agonistic interaction (Fig. 1d-f). The lack of video footage prevents us from making any final conclusion with regard to which animal is the more active one or initiating the different movements of the two sharks.

The duration of the photo record allows closer examination of one of the patterns, the 'pectoral bite'. For the whole 
duration of the sequence, male A does not tightly 'grasp' male B's right pectoral fin but only mouths the tip of the fin. Pair contact during elasmobranch mating events is usually maintained by the male's oral grasp of one of the female's pectoral fins [8-9], and it could therefore be expected to see male A continuing its grasp by moving its mouth up the pectoral fin of male B. While the reproductive behaviour pattern similar to 'pectoral bite' indeed can be seen during the sequence, its expression does not support a sexual motivation of the interaction. Furthermore, during the whole documented event, 'clasper flexion' (the erection of claspers; [7]) and 'crossing claspers' (a male overlapping both claspers until they point toward opposite side; [7]) as well as attempted copulation, probably impossible due to the anatomy of the male cloaca, could not be observed in either of the two male sharks. Based on the lack of intensity of the "pectoral bite' and the lack of clearly sexual behaviours such as clasper flexion or genital contact, we reject the hypothesis that the same-sex interaction was of sexual nature.

The most cogent explanation for this encounter is as an agonistic interaction expressing or establishing a dominance hierarchy between these two male sharks. This hypothesis is the most cited 'explanation' for why animals engage in same-sex interactions which may or may not have a sexual motivation (review in [22-23]) and holds that mounting is a display of dominance, while being mounted is a display of submission. Dominant individuals mount subordinates to reaffirm their position in the dominance hierarchy. For example, in a study on nurse sharks, more successful copulations were obtained by several larger males, which were identified as dominant, than by smaller males [7]. We identify our photographed males as "dominant" male A that bites the pectoral fin of the "subordinate" male B thereby expressing its dominance.

Very little is known about if and how elasmobranchs establish social hierarchies or how they maintain them, and such data are lacking completely for the zebra shark. Action patterns performed in agonistic contexts are typically also used in other contexts, such as mating and vice versa. The biting of the pectoral fins is an integral part of some elasmobranch mating, but intrasexual hierarchies in elasmobranchs may be expressed as well through biting behaviour. Male biting is often also involved when a female shark does not want to mate with a male conspecific. We compare our male zebra sharks to the female nurse shark caught in an unwanted 'pectoral bite' that will 'arch' her body away from the male and may eventually escape [19]. In addition to the "pectoral bite' recorded throughout the zebra shark sequence (Fig. 1ao), male B is 'arching' away from male A (Fig. 1d-o). Perhaps arching away is a universal response to any shark to shark bite in any circumstance.

It is possible that male A mistook male B for an adult female shark. The mistaken identity hypothesis claims that male - male interactions that might include sexual behaviour patterns occur because males mistake other males for females [24]. This has been proposed for same-sex sexual behaviour in insects [25] and birds [26] and has some precedence for elsamobranchs. Work with Atlantic stingrays [18] revealed fresh bite wounds on adults of both sexes during the full duration of the mating season and suggested that bite wounds on males may result from premating courtship attacks by males because females cannot be visually discriminated by the reproductively active males. It is unknown whether the described interaction occurred during a mating period. The season of zebra shark mating is unknown and evidence for sexual activity or relationships in adult sharks outside of the mating season other than sexual segregation is lacking for any species.

In conclusion, although the behaviours recorded were patterned in similar ways to elasmobranch male - female courtship and mating to some extent, we reject the homosexual behaviour hypothesis because: (1) we cannot demonstrate how the behaviours are distinct from non-sexual same-sex social interactions, (2) we cannot determine whether the patterns observed differ in their expression from more generalised patterns of social affiliation and, (3) no genital contact, clasper erection or attempted copulation occurred. Our analysis supports the hypothesis that the behaviours were of an agonistic nature, namely because biting is an important part of agonistic interactions in sharks and other animals. As with other one-time observations of difficult to document aspects of elasmobranch biology [1-2, 5, 9], our short documentation and interpretation will hopefully stimulate similar records in the future that will eventually shed light on action patterns that are used both in agonistic and mating contexts and help discern the underlying motivation.

\section{ACKNOWLEDGEMENTS}

We thank Mrs. Petra Gangolf for allowing us to use her excellent set of underwater photographs for our analysis. We also thank the diving guides and staff from Sea Bees Diving, Thailand, for valuable information on zebra shark sightings around Phuket Island. JMB was supported by the Shark Foundation Switzerland, the Save Our Seas Foundation and grant No. $119305 / 1$ from the Swiss National Science Foundation.

\section{REFERENCES}

[1] Brunnschweiler JM. Water-escape velocities in jumping blacktip sharks. J R Soc Interface 2005; 2: 389-391.

[2] Brunnschweiler JM, Andrews PLR, Southall EJ, Pickering M, Sims DW. Rapid voluntary stomach eversion in a free-living shark. J Mar Biol Ass UK 2005; 85: 1141-1144.

[3] Hallacher LE. On the feeding behavior of the basking shark, $\mathrm{Ce}$ torhinus maximus. Environ Biol Fishes 1977; 2: 297-298.

[4] Wilson SG. Basking sharks (Cetorhinus maximus) schooling in the southern Gulf of Maine. Fish Oceanogr 2004; 13: 283-286.

[5] Tricas TC, LeFeuvre EM. Mating in the reef white-tip shark, Triaenodon obesus. Mar Biol 1985; 84: 233-237.

[6] Harvey-Clark CJ, Stobo WT, Helle E, Mattson M. Putative mating behavior in basking sharks off the Nova Scotia coast. Copeia 1999: 780-782.

[7] Pratt HL Jr, Carrier JC. A review of elasmobranch reproductive behavior with a case study on the nurse shark, Ginglymostoma cirratum. Environ Biol Fishes 2001; 60: 157-188.

[8] Chapman DD, Corcoran MJ, Harvey GM, Malan S, Shivji MS. Mating behavior of southern stingrays, Dasyatis americana (Dasyatidae). Environ Biol Fishes 2003; 68: 241-245.

[9] Whitney NM, Pratt HL Jr, Carrier JC. Group courtship, mating behaviour and siphon sac function in the whitetip reef shark, Triaenodon obesus. Anim Behav 2004; 68: 1435-1442.

[10] Martin RA. A review of shark agonistic displays: comparison of display features and implications for shark-human interactions. Mar Freshw Behav Physiol 2007; 40: 3-34. 
[11] Bakeman R, Gottman JM. Observing Interaction: An Introduction to Sequential Analysis. Cambridge University Press: Cambridge 1986.

[12] Johnson RH, Nelson DR. Agonistic display in the gray reef shark, Carcharhinus menisorrah, and its relationship to attacks on man. Copeia 1973: 76-84.

[13] Myrberg AA Jr, Gruber SH. The behavior of the bonnethead shark, Sphyrna tiburo. Copeia 1974: 358-374.

[14] Gordon I. Pre-copulatory behavior of captive sandtiger sharks, Carcharias taurus. Environ Biol Fishes 1993; 38: 159-164.

[15] Barlow GW. Derivation of threat display in the gray reef shark. Mar Behav Physiol 1974; 3: 71-81.

[16] Stevens JD. The occurrence and significance of tooth cuts on the blue shark, Prionace glauca (L.) from British waters. J Mar Biol Ass UK 1974; 54: 373-378.

[17] Pratt HL Jr. Reproduction of the blue shark (Prionace glauca). US. Fish Bull 1979; 77: 445-470.

[18] Kajiura SM, Sebastian AP, Tricas TC. Dermal bite wounds as indicators of reproductive seasonality and behaviour in the Atlantic stingray, Dasyatis sabina. Environ Biol Fishes 2000; 58: 23-31.

[19] Pratt HL Jr, Carrier JC. Elasmobranch Courtship and Mating Behavior. In: Hamlett WC, Ed. Reproductive Biology and Phylogeny of Chondrichthyes: Sharks, Batoids and Chimaeras. Science Publishers 2005; 129-169.

[20] Carrier JC, Pratt HL Jr, Martin LK. Group reproductive behavior in free-living nurse sharks, Ginglymostoma cirratum. Copeia 1994: 646-656.

[21] Compagno LJV. Shark of the world. An annotated and illustrated catalogue of shark species known to date. Bullhead, mackerel and carpet sharks (Heterodontiformes, Lamniformes and Orectolobiformes). FAO Species Catalogue for Fishery Purposes FAO: Rome Vol. 2. No. 1, 2001.

[22] Bagemihl B. Biological Exuberance: Animal Homosexuality and Natural Diversity. St. Martin's Press: New York 1999.

[23] Vasey PL. Homosexual behavior in primates: a review of evidence and theory. Int J Primatol 1995; 16: 173-204.

[24] Vasey PL, Sommer V. Homosexual behaviour in animals: topics, hypotheses and research trajectories. In: Sommer V, Vasey PL, Eds. Homosexual Behaviour in Animals: An Evolutionary Perspective. Cambridge University 2006; 3-42.

[25] Thornhill R, Alcock J. The evolution of insect mating systems Harvard University Press: Cambridge 1983.

[26] Lombardo MP, Bosman RM, Faro CA, Houtteman SG, Kluisza TS. Homosexual copulations by male Tree Swallows. Wilson Bull 1994; 106: 555-557.

Received: April 28, 2008

Revised: May 12, 2008

Accepted: May 20, 2008

(C) Brunnschweiler and Pratt; Licensee Bentham Open.

This is an open access article licensed under the terms of the Creative Commons Attribution Non-Commercial License (http://creativecommons.org/licenses/by-nc/3.0/) which permits unrestricted, non-commercial use, distribution and reproduction in any medium, provided the work is properly cited. 